\title{
Article \\ Compact Ultra-Wideband Phase Inverter Using Microstrip-CPW-Slotline Transitions
}

\author{
Wahab Mohyuddin ${ }^{1}$, Gwan Hui Lee ${ }^{2}{ }^{\mathbb{D}}$, Dong Sik Woo ${ }^{3} \mathbb{D}$, Hyun Chul Choi ${ }^{2}$ and Kang Wook Kim ${ }^{2, *}$ \\ 1 Research Institute for Microwave and Millimeter-Wave Studies, National University of Sciences and \\ Technology (NUST), Islamabad 44000, Pakistan; wahab.mohyuddin@rimms.nust.edu.pk \\ 2 School of Electronic and Electrical Engineering, Kyungpook National University, Daegu 41566, Korea; \\ gwan6088@knu.ac.kr (G.H.L.); hcchoi@ee.knu.ac.kr (H.C.C.) \\ 3 School of Electronic \& Electrical Engineering, Daegu Catholic University, Gyeongsan 38430, Korea; \\ dswoo@cu.ac.kr \\ * Correspondence: kang_kim@ee.knu.ac.kr
}

\section{check for}

updates

Citation: Mohyuddin, W.; Lee, G.H.; Woo, D.S.; Choi, H.C.; Kim, K.W. Compact Ultra-Wideband Phase Inverter Using Microstrip-CPWSlotline Transitions. Electronics 2021, 10, 252. https://doi.org/10.3390/ electronics10030252

Received: 21 December 2020

Accepted: 18 January 2021

Published: 22 January 2021

Publisher's Note: MDPI stays neutral with regard to jurisdictional claims in published maps and institutional affiliations.

Copyright: (c) 2021 by the authors. Licensee MDPI, Basel, Switzerland. This article is an open access article distributed under the terms and conditions of the Creative Commons Attribution (CC BY) license (https:// creativecommons.org/licenses/by/ $4.0 /)$.

\begin{abstract}
A planar ultra-wideband phase inverter, which consists of a series of transitions between microstrip, coplanar waveguide, and slotline, is designed and implemented. This compact-sized phase inverter can be used to generate wideband $180^{\circ}$ phase differential signals, especially at high microwave frequencies up to millimeter-waves. The design is based on the impedance matching and smooth field transformation between the transitional stages. The fabricated transition has dimensions of $7.36 \mathrm{~mm} \times 5.08 \mathrm{~mm}$, and provides ultra-wide frequency bandwidth from $13 \mathrm{GHz}$ to $38 \mathrm{GHz}$ with low insertion loss of better than $2 \mathrm{~dB}$ within $\pm 5^{\circ}$ phase deviation and with return loss of greater than $10 \mathrm{~dB}$.
\end{abstract}

Keywords: transition; phase inverter; microstrip line; coplanar waveguide (CPW); slotline; ultra-wideband

\section{Introduction}

A phase inverter is used to generate $180^{\circ}$ phase differential signals, and, especially with the advent of 5 th generation mobile communications, wideband phase inverters have become important in modern microwave and millimeter-wave (mm-wave) systems. A series of applications inspired the investigation of generating differential signals for devices such as phase shifters [1], filters [2], hybrid ring couplers [3-5], and recently for antenna arrays [6] and measurement systems.

Recently, various studies have been conducted to design high-performance phaseinverting transitional structures using planar transmission lines such as microstrip line (MSL), coplanar waveguide (CPW), coupled lines, parallel stripline (PSL), slotline (SL), and substrate integrated waveguide (SIW) [7-14]. However, it is quite challenging to design a wideband structure with low insertion loss and good phase balance. Additionally, the structure should be compact in size and easy to be integrated with the system.

A design of a microwave $180^{\circ}$ phase shifter was presented in [8] using an MSL-CPWMSL transition. In this transition, low insertion loss performance from $5.5 \mathrm{GHz}$ to $18 \mathrm{GHz}$ was achieved. In ref. [9], a high-performing mm-wave phase inverter was introduced with a bandwidth of $28 \%$. In order to achieve a wide differential phase bandwidth, a combination of parallel-coupled lines and L-shaped networks was used [10], where line spacing and input/output matching limited the phase inverter bandwidth and performance at high frequencies. In ref. [11], a $180^{\circ}$ phase shifter structure using a parallel-coupled line was proposed to improve the bandwidth, but the operating frequency was limited to low microwave frequencies. In ref. [12], an SIW-based phase inverter was proposed with high performance at mm-waves, but the fractional bandwidth was only $42.42 \%$.

Additionally, a pair of transitions from MSL-SL was designed for a $180^{\circ}$ phase shifter [13], where the highest operating frequency was limited to $12 \mathrm{GHz}$ due to the 
coupling structure and thickness of the substrate. Furthermore, a pair of ultra-wideband (UWB) transitions for phase inversion applications was reported in [14] by the authors' group. These transitions comprised various transitions from MSL-CPW to CPW-PSL, and then to PSL-MSL, where the $180^{\circ}$ phase shift was achieved up to $25 \mathrm{GHz}$. The phase inverter performed excellently up to $\sim 25 \mathrm{GHz}$, but the transition design configuration was not practical to be implemented at $\mathrm{mm}$-wave frequencies.

In this study, a new design method of the planar UWB phase inverter using a series of MSL-CPW-SL transitions is proposed. The proposed transition can be implemented as a simple and compact structure for phase inversion applications at high microwave frequencies up to mm-waves, and it is flexible enough to be integrated with other components or systems.

\section{Design of the Phase Inverter}

Figure 1 illustrates the proposed phase inverter consisting of three planar transitions, i.e., MSL-to-CPW, CPW-to-SL, and SL-to-MSL transitional structures. In the proposed configuration, the signal line of the MSL is connected through a via to the center signal line of the CPW formed on the bottom of the substrate. The ground plane of the MSL is split into two paths to form the ground planes of the CPW. Two slots of the CPW are converted into two slotlines, and a circular stub terminates each of the slotlines. Additionally, each slotline is converted back to an MSL on the top plane using a via, and the two MSLs are combined to form an MSL.

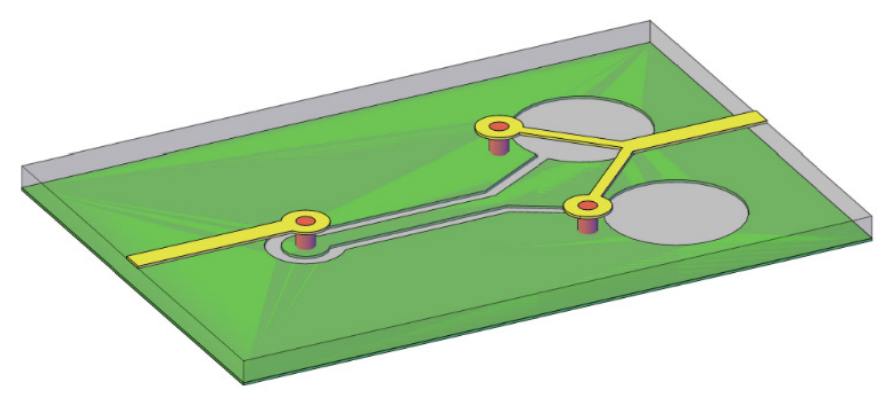

Figure 1. Perspective view of the proposed ultra-wideband (UWB) phase inverter consisting of a series of microstrip-coplanar waveguide (CPW)-slot transitions.

The CPW impedance can be adjusted by the slot width and center signal line width, and impedances of the MSL and CPW are kept as $50 \Omega$ in this design. In a CPW, a signal propagates as an unbalanced signal in the even mode of the coupled slotlines of the CPW [15]. This mode of the CPW is then smoothly converted into two slotlines by gradually increasing the width of the center strip of the CPW with an angle of $60^{\circ}$, as shown in Figure 2. The impedance of the slotlines is selected as $82 \Omega$ because it is impractical to design a $50 \Omega$ slotline on a high dielectric substrate using a conventional etching process.

To achieve ultra-wide bandwidth and efficient transformation from SL to MSL, each slotline that is branched out from the CPW at the bottom side is terminated with an inductive circular stub with a diameter of $d_{r}$, which acts as a virtual open circuit load [16]. Additionally, each slotline is coupled with the top-side MSL through a via. These two $70 \Omega$ MSLs are then combined with a $40 \Omega$ MSL, which is then tapered to the $50 \Omega$ MSL. The lengths of the CPW, MSLs, and SLs are selected as $\lambda \mathrm{g} / 4$, where $\lambda \mathrm{g}$ is the guided wavelength of the corresponding line at $15 \mathrm{GHz}$.

In the design process of the proposed phase inverter consisting of cascaded transitions, it should be noted that the effective dielectric constant $\left(\varepsilon_{e f f}\right)$ varies along the position of the transitional structure. The $\varepsilon_{\text {eff }}$, thus the phase shift, changes depending on the field distribution shape of the transition section through the dielectric and air. The $\varepsilon_{\text {eff }}$ values at various sections of the transition are calculated using the conventional propagation velocity formula, where the propagation constants are calculated with the help of the electromagnetic (EM) simulator. The calculated $\varepsilon_{\text {eff }}$ values are listed in Table 1, where 
the used substrate is the Rogers RT/Duroid 6010 with thickness of 10 mil and dielectric constant of 10.2. In this design example, the length of the proposed transition is kept as 290 mil $(7.36 \mathrm{~mm})$. The actual length of the transition is longer than that of the MSL (290 mil) due to the bended structures and a via before and after the D-D' section in Figure 2. The phase inversion occurs at the via connection ( $\mathrm{D}^{\left.-\mathrm{D}^{\prime}\right)}$ between the signal line and ground line. The lengths of the bended structures $\left(\lambda_{g(s l o t) / 4}\right.$ and $\left.\lambda_{g(M L) / 4}\right)$ are slightly adjusted to obtain an equivalent averaged $\varepsilon_{e f f}$ between the proposed transition and a straight microstrip line for the best phase inversion pair.

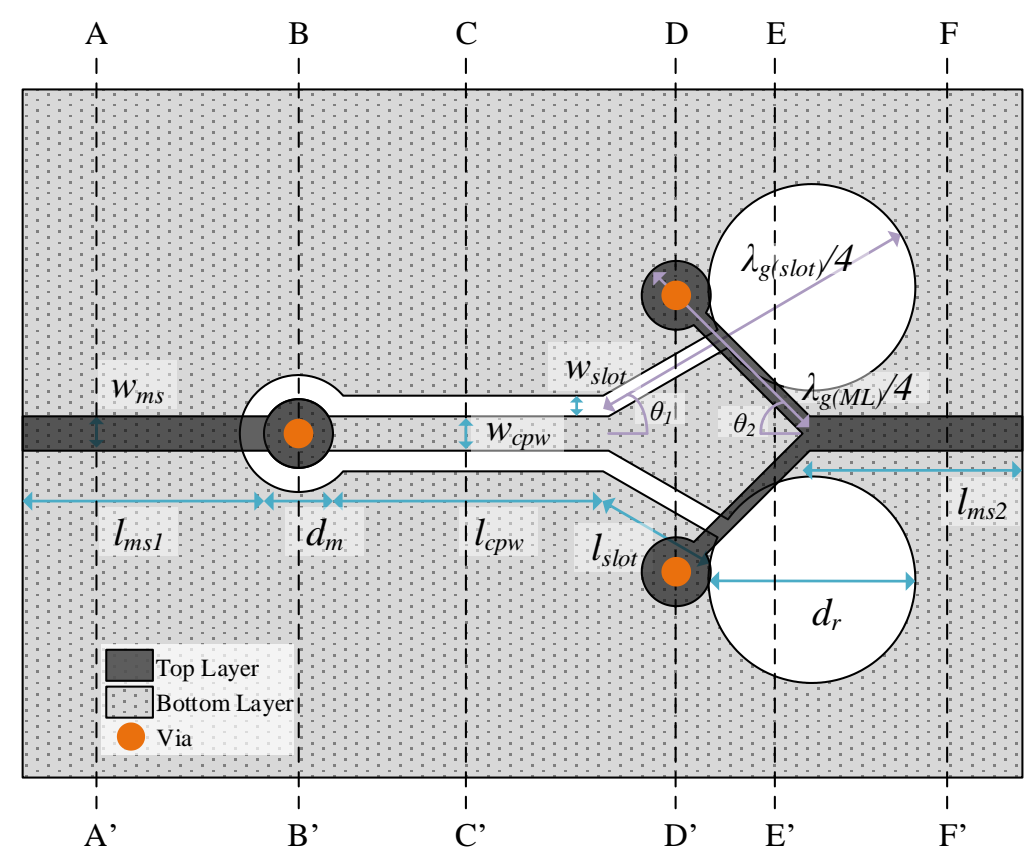

Figure 2. Layout of the proposed UWB phase inverter. Dimensions: $w_{\mathrm{ms}}=10, w_{\mathrm{cpw}}=10, w_{\mathrm{slot}}=6$, $l_{\mathrm{ms} 1}=80, d_{\mathrm{m}}=20, l_{\mathrm{cpw}}=90, l_{\text {slot }}=40, d_{\mathrm{r}}=60, d_{\mathrm{via}}=8, l_{\mathrm{ms} 2}=64, \lambda_{\mathrm{g}(\text { slot }) / 4}=100, \lambda_{\mathrm{g}(\mathrm{ML}) / 4}=80$ (units: mil), $\theta_{1}=60^{\circ}, \theta_{2}=45^{\circ}$.

Table 1. Effective dielectric constants along the transition.

\begin{tabular}{cccccc}
\hline A-A $^{\prime}$ & B-B $^{\prime}$ & C-C $^{\prime}$ & D-D $^{\prime}$ & E-E' $^{\prime}$ & F-F $^{\prime}$ \\
\hline 6.73 & 4.20 & 5.09 & 3.20 & 6.33 & 6.73 \\
\hline
\end{tabular}

Figure 3 shows simplified electric field distributions for different cross-sections of the proposed transition. From Figure 3, it is observed that the electric field distribution of the MSL is mostly vertical from the top to the bottom side of the substrate $\left(\mathrm{A}-\mathrm{A}^{\prime}\right)$, and the field distribution of the CPW on the bottom side is mostly horizontal from center strip to side conductors (C-C'). One via and split ground planes at B-B' help to smoothly convert the field distribution from mostly vertical (A-A') to mostly horizontal (C-C') shapes. Additionally, another via for each slotline converts from a mostly horizontal field of the SL to a mostly vertical field of the MSL (E- $\left.E^{\prime}\right)$, at which the phase inversion takes place. Finally, the two MSLs are combined to form a single MSL (F-F'). 


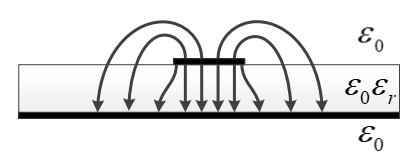

A-A
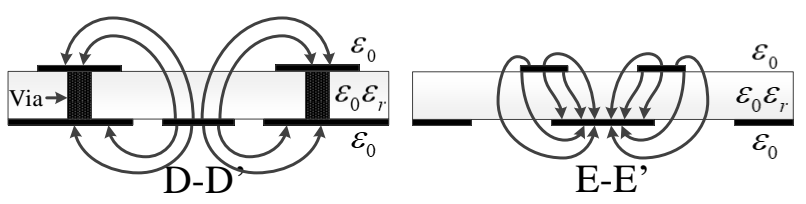

E-E'

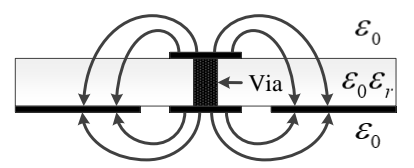

B-B'

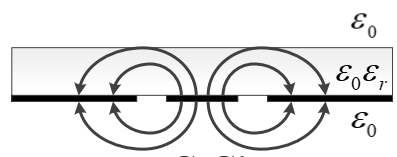

C-C'

Figure 3. Cross-sectional views of simplified electric field distributions.

The cross-section of the finite MSL (E-E') is represented in Figure 4. Due to the symmetry, the right-hand side of the E-E' section is considered for the analysis. The electric field distribution is divided by six regions. Each region is analyzed by the conformal mapping to calculate the characteristic impedance of each cross-section. The characteristic impedance and $\varepsilon_{\text {eff }}$ of the cross-section of the MSL with finite ground plane is calculated by obtained capacitances following the guidelines described by the authors' group in [17-19].

$$
\begin{gathered}
Z_{0}=\frac{120 \pi}{\sqrt{\varepsilon_{\text {eff }}}\left(C_{1}^{\prime}+C_{2}^{\prime}+C_{3}^{\prime}+C_{4}^{\prime}+C_{5}^{\prime}+C_{6}^{\prime}\right) / \varepsilon_{0}} \\
\varepsilon_{\text {eff }}=\frac{C_{1}+C_{2}+C_{3}+C_{4}+C_{5}+C_{6}}{C_{1}^{\prime}+C_{2}^{\prime}+C_{3}^{\prime}+C_{4}^{\prime}+C_{5}^{\prime}+C_{6}^{\prime}}
\end{gathered}
$$

where $C_{1}, C_{2}, C_{3}, C_{4}, C_{5}$, and $C_{6}$ are the capacitances of each of the six regions, respectively. $C_{1}^{\prime}, C_{2}^{\prime}, C_{3}^{\prime}, C_{4}^{\prime}, C_{5}^{\prime}$, and $C_{6}^{\prime}$ are the capacitances of the air area in each region.

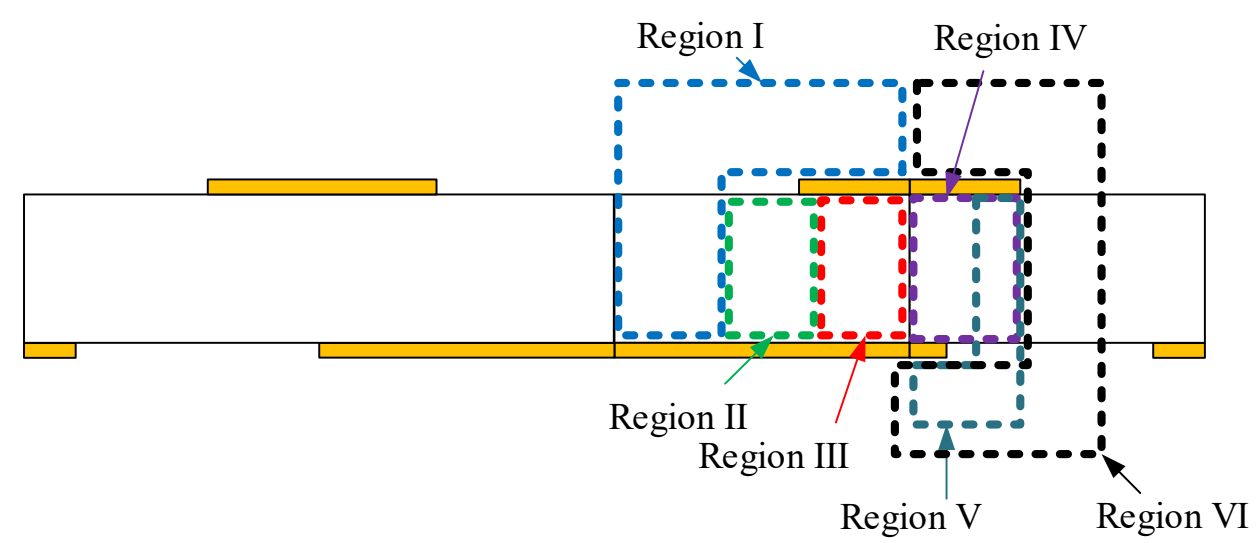

Figure 4. Cross-sectional view of simplified electric field distributions at E-E'.

With the obtained $\varepsilon_{e f f}$, the total electric lengths of the proposed transition with calculation and simulation are $335^{\circ}$ and $337^{\circ}$, respectively, with the phase inversion (D$\left.\mathrm{D}^{\prime}\right)$ at $15 \mathrm{GHz}$. The $\varepsilon_{\text {eff }}$ value from A-A' to D-D' is calculated using the conventional MSL, CPW, and SL analyses [15]. The $\varepsilon_{e f f}$ value from D-D' to E-E' is calculated by using Equation (2). Finally, the $\varepsilon_{\text {eff }}$ value from E-E' to F-F' is calculated using the MSL analysis [15]. The calculated and simulated electric lengths of the reference MSL are $344^{\circ}$ and $347^{\circ}$ at $15 \mathrm{GHz}$, respectively. Therefore, the proposed transition can be used as a phase inverter in combination with the same-length MSL.

\section{Implementation and Measurements}

The proposed phase inverter consisting of a series of transitions is fabricated on the Rogers RT/Duroid 6010 substrate (thickness of 10 mil, dielectric constant of 10.2, and tangent loss of 0.0023). Figure 5 shows the top and bottom views of the fabricated 
phase inverting transition with the reference MSL. The size of the fabricated transition is $290 \mathrm{mil} \times 200 \mathrm{mil}(7.36 \mathrm{~mm} \times 5.08 \mathrm{~mm})$.

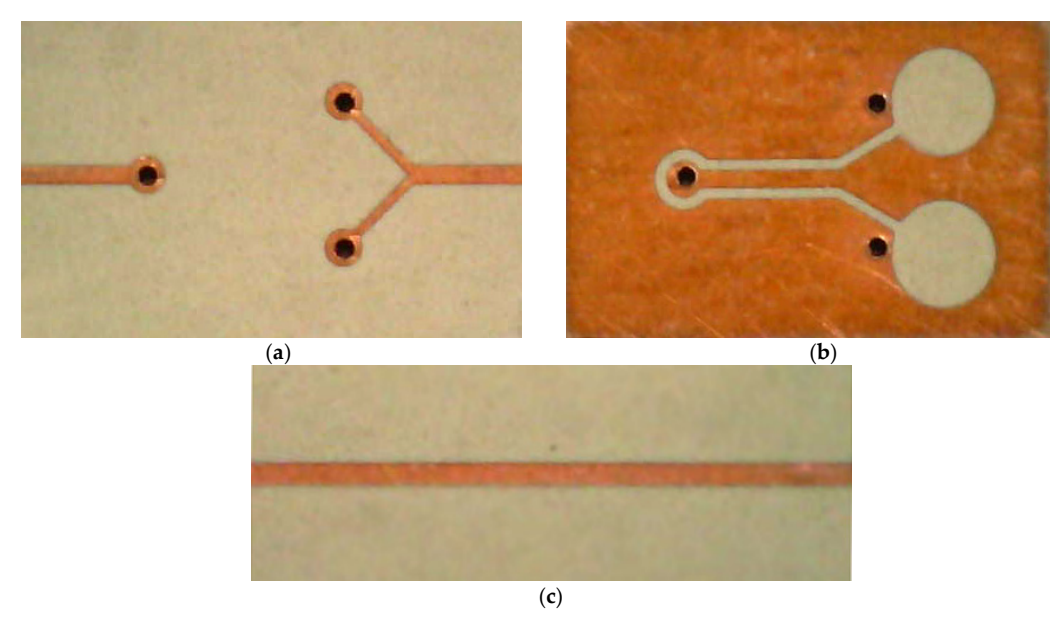

Figure 5. Fabricated UWB phase inverter: (a) top view, (b) bottom view, (c) top view of the reference microstrip line. The dimensions are $290 \mathrm{mil} \times 200 \mathrm{mil}(7.36 \mathrm{~mm} \times 5.08 \mathrm{~mm})$.

The simulation of the proposed transition was performed with a 3D EM simulator (CST Microwave Studio). For the measurements, an Anritsu MS4644B vector network analyzer (VNA) with a universal test fixture was used. The short-open-load-through (SOLT) calibration method was adopted for the VNA calibration. The measured and simulated results of the planar ultra-wideband phase inverter are shown in Figure 6. The insertion loss of the fabricated phase inverter is better than $2 \mathrm{~dB}$ from $8 \mathrm{GHz}$ to $39 \mathrm{GHz}$, and the maximum insertion loss is $0.9 \mathrm{~dB}$ at the frequencies below $30 \mathrm{GHz}$. The return loss of the fabricated phase inverter is greater than $10 \mathrm{~dB}$ over the frequency range from $8 \mathrm{GHz}$ to $39 \mathrm{GHz}$. Some minor discrepancies between the simulated and measured results at the high frequency might have occurred due to fabrication inaccuracy and the high loss tangent of the substrate. It may be challenging to design the proposed transition for frequencies higher than $40 \mathrm{GHz}$ since the substrate used in the design example is lossy at high frequencies. However, at above $40 \mathrm{GHz}$, the proposed transition can be designed on low-loss tangent substrates, still achieving good performance with further miniaturization. Figure 7 shows the phase difference between the proposed fabricated phase inverter and a reference $50 \Omega$ microstrip line. The phase difference is observed to be less than $\pm 5^{\circ}$ over the wide range of frequencies from $13 \mathrm{GHz}$ to $38 \mathrm{GHz}$.

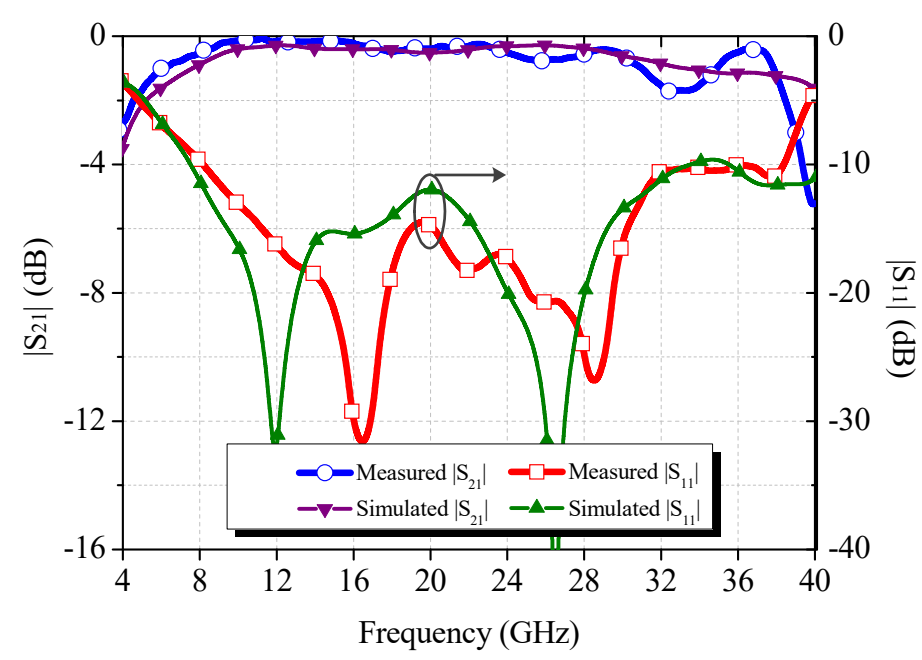

Figure 6. Measured and simulated S-parameters of the fabricated phase inverter. 


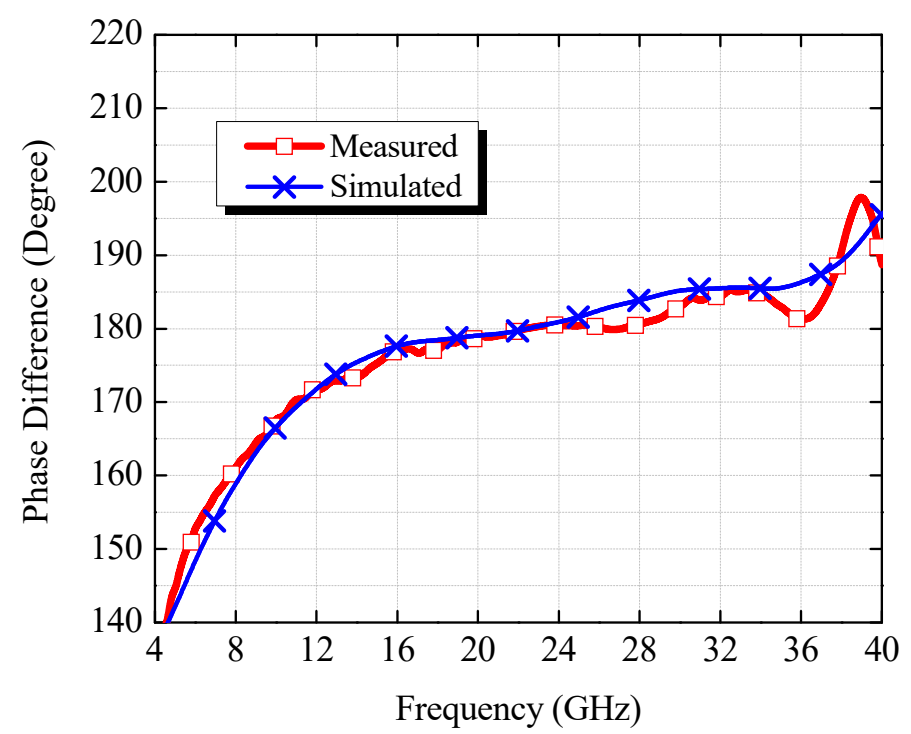

Figure 7. Measured and simulated phase differences of the fabricated phase inverter.

The performance comparison of the proposed phase inverter transition as compared with recently reported ones is summarized in Table 2 . It can be noted that the proposed phase inverter provides obvious advantages of the operating frequency range with low insertion loss, design flexibility, good phase balance, and compact size. However, the main advantage of the proposed phase inverter is its application in the mm-wave band.

Table 2. Performance comparison between reported $180^{\circ}$ phase inverters.

\begin{tabular}{cccccc}
\hline Ref. & Max PD $^{\left({ }^{\circ}\right)}$ & IL (dB) & RL (dB) & BW (\%) & FR (GHz) \\
\hline$[5]$ & \pm 25 & N/A & $>10$ & 120 & $1-4$ \\
{$[9]$} & \pm 4.6 & $<1.48$ & $>10$ & 28.01 & $24.4-32.35$ \\
{$[10]$} & \pm 8 & $<1.3$ & $>10$ & 100 & $1-3$ \\
{$[11]$} & 5 & $<0.5$ & $>15$ & 83.9 & $1.14-2.79$ \\
{$[12]$} & \pm 2.9 & $<2.66$ & $>12.7$ & 42.42 & $26-40$ \\
{$[13]$} & \pm 3.6 & $<2.1$ & $>10$ & 142.8 & $2-12$ \\
{$[14]$} & \pm 5 & $<1.8$ & $>10$ & 169 & $2.1-25$ \\
TW & \pm 5 & $<2$ & $>10$ & 98.04 & $13-38$
\end{tabular}

PD: phase deviation, IL: insertion loss, RL: return loss, BW: bandwidth, FR: operating frequency range, TW: this work.

\section{Conclusions}

A new design method of the planar UWB phase inverter consisting of cascaded microstrip-CPW-slotline transitions is described. The design is based on the impedance matching and smooth field transformation. The proposed phase inverter provides ultrawide bandwidth and good phase balance with compact size and design flexibility at higher microwave frequencies up to $\mathrm{mm}$-waves. The implemented phase inverter has an insertion loss of less than $2 \mathrm{~dB}$ and good phase balance in the frequency range of $13 \mathrm{GHz}$ to $38 \mathrm{GHz}$.

Author Contributions: Conceptualization, W.M. and G.H.L.; methodology, W.M.; software, W.M.; validation, W.M.; formal analysis, W.M. and G.H.L.; investigation, W.M.; resources, W.M.; data curation, W.M.; writing-original draft preparation, W.M.; writing-review and editing, W.M., G.H.L., D.S.W., and K.W.K.; visualization, W.M.; supervision, D.S.W., H.C.C., and K.W.K.; project administration, H.C.C. and K.W.K.; funding acquisition, K.W.K. All authors have read and agreed to the published version of the manuscript.

Funding: This research was funded by the Ministry of Education, Science and Technology and the Ministry of Education, Korea. 
Acknowledgments: This work was supported by the National Research Foundation of Korea (NRF) grant funded by the Korean government (NRF-2018R1D1A3B07047848).

Conflicts of Interest: The authors declare no conflict of interest.

\section{References}

1. Hagiwara, K.; Arai, H. Wideband unbalanced fed 180-degree phase shifter using phase inverter. In Proceedings of the 2013 IEEE International Workshop on Electromagnetics, Applications and Student Innovation Competition, Kowloon, China, 1-3 August 2013; 76-77. [CrossRef]

2. Wong, K.W.; Chiu, L.; Member, S.; Xue, Q.; Member, S. Wideband Parallel-Strip Bandpass Filter Using Phase Inverter. IEEE Microw. Wirel. Compon. Lett. 2008, 18, 503-505. [CrossRef]

3. Wu, T.W.K. Size-reduction and band-broadening design technique of uniplanar hybrid ring coupler using phase inverter for M(H)MIC's. IEEE Trans. Microw. Theory Tech. 1999, 47, 198-206. [CrossRef]

4. Kim, Y.-G.; Song, S.-Y.; Kim, K.W. A Compact Wideband Ring Coupler Utilizing a Pair of Transitions for Phase Inversion. IEEE Microw. Wirel. Compon. Lett. 2011, 21, 25-27. [CrossRef]

5. Mo, T.T.; Xue, Q.; Chan, C.H. A broadband compact microstrip rat-race hybrid using a novel CPW inverter. IEEE Trans. Microw. Theory Tech. 2007, 55, 161-166. [CrossRef]

6. Hasan, M.N.; Seo, M. High-gain $2 \times 2$ UWB antenna array with integrated phase inverter. Electron. Lett. 2018, 54, 177-187. [CrossRef]

7. Riaan, F.; Johan, J. A broadband $180^{\circ}$ hybrid ring coupler using a microstrip-to-slotline inverter. Microw. Opt. Technol. Lett. 2015, 57, 2164-2168. [CrossRef]

8. Eldek, A.A. Wideband $180^{\circ}$ phase shifter using Microstrip-CPW-microstrip transition. Prog. Electromagn. Res. B 2008, 2, 177-187. [CrossRef]

9. Huang, J.; Wang, Q.; Li, Z.; Yang, L. Novel method for millimeter wave phase shifter design using loaded transmission line. Asia Pac. Microw. Conf. Proc. APMC 2017, 7-10. [CrossRef]

10. Guo, L.; Zhu, H.; Abbosh, A. Wideband Phase Shifter with Wide Phase Range Using Parallel Coupled Lines and L-Shaped Networks. IEEE Microw. Wirel. Compon. Lett. 2016, 26, 592-594. [CrossRef]

11. Yoon, H.J.; Min, B.W. Wideband $180^{\circ}$ phase shifter using parallel-coupled three-line. IEEE Microw. Wirel. Compon. Lett. 2019, 29, 89-91. [CrossRef]

12. Peng, H.; Zhao, F.; Tatu, S.O.; Dong, J.; Yang, T. Empty substrate-integrated waveguide phase inverter in millimetre-wave band application. Electron. Lett. 2020, 56, 382-385. [CrossRef]

13. Tebache, S.; Ghanem, F.; Belouchrani, A.; Mansoul, A. Novel flowchart design of frequency independent $180^{\circ}$ phase shifters. Microw. Opt. Technol. Lett. 2019, 61, 136-140. [CrossRef]

14. Kim, Y.G.; Song, S.Y.; Kim, K.W. A pair of ultra-wideband planar transitions for phase inversion applications. IEEE Microw. Wirel. Compon. Lett. 2010, 20, 492-494. [CrossRef]

15. Gupta, K.C.; Garg, R.; Bahl, I.; Bhartia, P. Microstrip Lines and Slotlines; Artech House: London, UK, 1996.

16. Guo, Z.; Yang, T. Novel compact ultra-wideband bandpass filter based on vialess vertical CPW/microstrip transitions. Electron. Lett. 2017, 53, 1258-1260. [CrossRef]

17. Lee, G.H.; Mohyuddin, W.; Choi, H.C.; Kim, K.W. Asymmetric Ultra-Wideband Microstrip-to-Coplanar Stripline Transition. IEEE Microw. Wirel. Compon. Lett. 2018, 28, 386-388. [CrossRef]

18. Lee, J.S.; Lee, G.H.; Mohyuddin, W.; Choi, H.C.; Kim, K.W. Design of an ultra-wideband microstrip-to-slotline transition on low-permittivity substrate. Electronics 2020, 9, 1-14. [CrossRef]

19. Lee, G.H.; Kim, D.H.; Mohyuddin, W.; Kumar, S.; Choi, H.C.; Kim, K.W. Design of an Ultra-wideband Coplanar Strip-to-Parallel Stripline Transition Using an Analytical Model Based on Conformal Mapping. Microw. Opt. Technol. Lett. 2020. [CrossRef] 